\title{
Sensory discrimination as related to general intelligence
}

\author{
G. Scott Acton ${ }^{\mathrm{a}, *}$, David H. Schroeder ${ }^{\mathrm{b}}$ \\ ${ }^{a}$ University of California, San Francisco, Box 0984-TRC, 401 Parnassus Avenue, \\ San Francisco, CA, 94143-0984, USA \\ ' Johnson O'Connor Research Foundation, Chicago, IL USA
}

Received 15 November 1999; received in revised form 15 May 2000; accepted 8 August 2000

\begin{abstract}
The hypothesis, originally proposed by Galton and elaborated by Spearman, that there is a functional correspondence between sensory discrimination and general intelligence $(g)$ continues to spark debate. Previous findings suggest that pitch discrimination and tactile discrimination are only weakly correlated with $g$. This study sought to replicate the pitch discrimination findings and to expand them to the modality of color discrimination in a large sample $(N=899)$ by correlating two sensory discrimination measures with the general factor from a battery of 13 cognitive-ability tests. The modest correlations found between $g$ and measures of pitch discrimination $(r=.21)$ and color discrimination $(r=.31)$ suggest that sensory discrimination is relatively distinct from general intelligence. Although consistent with the neural processing speed explanation of $g$, these results cast doubt on a strong form of the sensory discrimination explanation of $g$. (C) 2001 Elsevier Science Inc. All rights reserved.
\end{abstract}

Keywords: Sensory discrimination; General intelligence; Pitch discrimination; Color discrimination

\section{Introduction}

The central importance of sensory discrimination to theories of intelligence can be traced to Galton's (1883) hypothesis that individual differences in mental ability are correlated with fine differences in sensory discrimination. Sensory discrimination was introduced to provide a mechanism linking intelligence to heredity. Galton believed that ancestral inheritance

\footnotetext{
* Corresponding author.
}

E-mail address: acton@itsa.ucsf.edu (G.S. Acton). 
influences the development of the nervous system and that differences in the nervous system influence basic information-processing abilities.

Two schools of thought arose on the nature of the basic information-processing abilities suggested by Galton to underlie intelligence. Spearman (1904) took Galton's proposed mechanism of sensory discrimination so seriously that he virtually equated intelligence with sensory discrimination. This strong form of the sensory discrimination explanation requires not only a correlation between sensory discrimination and intelligence - such as Galton's hypothesis suggests - but a strong correlation. Cattell (1886a, 1886b), on the other hand, held that the elementary basis of intelligence is information processing speed. Because this explanation suggests a different mechanism for explaining intelligence, it is consistent with a weak correlation between sensory discrimination and intelligence. Both hypotheses, when tested early on, were widely regarded as having been disconfirmed, after which they lay dormant for many decades, but both are now experiencing something of a renaissance (Deary, 1986, 1994b; Jensen, 1998).

Had Spearman known initially of the results of investigators such as Sharp (1898) and Wissler (1901) — which he became aware of and cited in his 1904 article - he never would have completed the important study on which his 1904 article was based. As it happened, Spearman (1904) went on to test his theory of a strong relation between sensory discrimination and intelligence using a method adequate for assessing this relation. Theoretically, he regarded sensory discrimination as the simplest form of mental operation that was clearly intellective. Methodologically, he used the correlation corrected for attenuation due to unreliability. Armed with this theory and method, Spearman reached "the profoundly important conclusion that there really exists a something that we may provisionally term 'General Sensory Discrimination' and similarly a 'General Intelligence,' and further that the functional correspondence between these two is not appreciably less than absolute" (Spearman, 1904, p. 272, italics omitted).

The debate surrounding sensory discrimination as a mechanism for $g$ has continued in the recent literature on auditory inspection time (AIT). Irwin (1984) and Raz, Willerman, and Yama (1987) have lent support to the Spearman position, claiming that the correlation between AIT and intelligence is due to the relation of AIT to pitch discrimination. Deary (1994a), Deary, Caryl, Egan, and Wight (1989), and Deary, Head, and Egan (1989), by contrast, have sided with Cattell, claiming that the correlation between AIT and intelligence is separable from the relation of AIT to pitch discrimination. Both the Spearman and Cattell explanations suggest an important role for elementary information processing in explaining $g$; the Spearman explanation, however, rules out the possibility of a negligible relation between measures of sensory discrimination and $g$. Despite one study of tactile discrimination that found evidence for weak associations with $g(\mathrm{Li}$, Jordanova, \& Lindenberger, 1998), these hypotheses have up to now been tested primarily in the auditory modality using only small samples.

This article reports a study of the relations of two tests of sensory discrimination with a broad battery of other ability tests and with the $g$ factor derived therefrom. The purpose is to shed light on the relations between sensory discrimination and other abilities - and, more specifically, to assess the relations between multiple forms of sensory discrimination and general intelligence. 


\section{Method}

\subsection{Participants}

The sample comprised 899 examinees who came to the Johnson O'Connor Research Foundation (JOCRF) during 1997 to take a battery of tests to learn about their abilities, typically for career-planning purposes. Examinees generally had either graduated from college, were in college, or were college-bound and were distributed across the ability range of that group. Over half of the examinees were tested at the JOCRF's New York office $(n=470)$, with the remainder tested in Atlanta $(n=191)$ and Boston $(n=238)$. Most examinees were white upper middle-class teens or adults ranging in age from 13 to 62 $(M=27.4$, S.D. $=10.3)$. Approximately half of the examinees were males $(n=459)$.

\subsection{Measures}

\subsubsection{JOCRF standard battery}

The JOCRF standard battery consists of 19 ability tests, including 13 tests of cognitive abilities (e.g., Memory for Design), three auditory ability tests (including Pitch Discrimination), two dexterity tests, and a test for colorblindness. The specific traits measured by the tests and the tests' reliabilities are shown in Table 1. The validities of the tests have been assessed in hundreds of studies over many years, as reported in the JOCRF's technical reports (e.g., Daniel, 1982, 1983; Tal, 1986; Zimowski \& Wothke, 1988). The battery of tests as a whole is thought to be useful for career guidance. Because the battery is designed to provide broad coverage of the cognitive-ability domain, it is well suited to the derivation of major cognitive-ability factors such as $g$.

\subsubsection{Farnsworth-Munsell 100-Hue Test}

The 100-Hue Test (Farnsworth, 1957) is a test of color discrimination. It is composed of four rows of 23 color caps. Each cap bears a single hue on top and is numbered on bottom according to its appropriate placement in the row, with consecutively numbered caps meant to occupy adjacent positions. An examinee is instructed to place caps in order according to the similarity of their color, with caps initially occupying random positions between two fixed caps at each end of a row. Errors are recorded when caps are placed in positions other than those indicated by their numbered positions. Initial error scores were computed in accordance with the specifications in the test manual (Farnsworth, 1957). Because this yielded skewed scores, we then took the square root of the score for each cap before calculating row and total scores. For the correlational and factor analyses, we reflected the scores so that higher scores would indicate greater ability. The alpha reliability of row scores in these transformed data was .86 .

\subsubsection{Pitch Discrimination}

The JOCRF Pitch Discrimination test is adapted from the corresponding test in the Seashore Measures of Musical Talent (Seashore, Lewis, \& Saetveit, 1940). Examinees are presented with 80 pairs of tones and must report which tone in each pair is higher in pitch. 
Table 1

Correlations of tests of sensory discrimination with tests of other abilities

\begin{tabular}{|c|c|c|c|c|}
\hline Test & Reliability & Trait measured & 100-Hue & Pitch Discrimination \\
\hline \multicolumn{5}{|l|}{ Cognitive abilities } \\
\hline \multicolumn{5}{|l|}{ Spatial ability } \\
\hline Paper Folding & .82 & Structural visualization & .32 & .26 \\
\hline Wiggly Block & .73 & Structural visualization & .23 & .16 \\
\hline \multicolumn{5}{|l|}{ Numerical ability } \\
\hline Number Series & .87 & Numerical reasoning & .29 & .20 \\
\hline Number Facility & .86 & Computational ability & .16 & .11 \\
\hline \multicolumn{5}{|l|}{ Memory } \\
\hline Memory for Design & .80 & $\begin{array}{l}\text { Memory for straightline } \\
\text { patterns }\end{array}$ & .28 & .17 \\
\hline Observation & .62 & $\begin{array}{l}\text { Memory for fine visual } \\
\text { details }\end{array}$ & .16 & .09 \\
\hline Number Memory & .82 & Memory for numbers & .16 & .09 \\
\hline Silograms & .92 & $\begin{array}{l}\text { Associative memory for } \\
\text { verbal material }\end{array}$ & .09 & .03 \\
\hline \multicolumn{5}{|l|}{ Convergent thinking } \\
\hline Analytical Reasoning & .81 & $\begin{array}{l}\text { Ability to arrange ideas } \\
\text { into a logical sequence } \\
\text { quickly }\end{array}$ & .21 & .14 \\
\hline Inductive Reasoning & .84 & $\begin{array}{l}\text { Quickness in seeing } \\
\text { relations }\end{array}$ & .19 & .05 \\
\hline \multicolumn{5}{|l|}{ Divergent thinking } \\
\hline Ideaphoria & .97 & Ideational fluency & .14 & .14 \\
\hline \multicolumn{5}{|l|}{ Vocabulary } \\
\hline English Vocabulary & .96 & $\begin{array}{l}\text { Knowledge of English } \\
\text { words }\end{array}$ & .23 & .20 \\
\hline \multicolumn{5}{|l|}{ Perceptual speed } \\
\hline Number Checking & .96 & $\begin{array}{l}\text { Clerical speed and } \\
\text { accuracy }\end{array}$ & .08 & .12 \\
\hline \multicolumn{5}{|l|}{ Noncognitive abilities } \\
\hline \multicolumn{5}{|l|}{ Visual perception } \\
\hline Color Perception & NA & Colorblindness & .30 & .05 \\
\hline \multicolumn{5}{|l|}{ Auditory ability } \\
\hline Tonal Memory & .91 & $\begin{array}{l}\text { Ability to remember } \\
\text { sequences of tones }\end{array}$ & .26 & .49 \\
\hline Rhythm Memory & .73 & $\begin{array}{l}\text { Ability to remember } \\
\text { rhythmic patterns }\end{array}$ & .22 & .33 \\
\hline \multicolumn{5}{|l|}{ Motor ability } \\
\hline Finger Dexterity & .86 & Fine manual dexterity & .20 & .11 \\
\hline Tweezer Dexterity & .93 & Small-instrument dexterity & .15 & .06 \\
\hline \multicolumn{5}{|l|}{ Sensory discrimination } \\
\hline 100-Hue & .86 & $\begin{array}{l}\text { Ability to perceive fine } \\
\text { differences in color }\end{array}$ & - & .22 \\
\hline Pitch Discrimination & .80 & $\begin{array}{l}\text { Ability to perceive fine } \\
\text { differences in pitch }\end{array}$ & .22 & - \\
\hline
\end{tabular}


The reference tone in each pair is $435 \mathrm{~Hz}$; in the easiest pair, the other tone is $445 \mathrm{~Hz}$, with pairs becoming progressively closer in pitch until the other tone is $437 \mathrm{~Hz}$. The test is fixedpace, with pairs of tones presented for $0.6 \mathrm{~s}$ each. Volume levels are controlled by each examinee, with tones presented on a tape player through headphones. Previous research showed the alpha reliability of the nine subparts of the test to be .80 (Daniel, 1980).

\subsection{Analyses}

In all analyses, we partialled the effects of gender out of the test scores. We also partialled each score for age and - because the relations with age were frequently curvilinear — for age-squared and age-cubed.

The correlations among the 100-Hue, Pitch Discrimination, and other standard battery tests were computed. To identify $g$, two principal-axis factor analyses were performed on the 13 cognitive-ability tests in the JOCRF battery. One analysis was based on a hierarchical model of cognitive abilities; in it we extracted all factors with initial eigenvalues greater than one and then rotated these factors to the promax criterion. The amount of intercorrelation between factors was determined by setting the kappa value to 1.8 . We then factored these factors, which yielded a single second-order factor with an initial eigenvalue greater than one, which we interpreted as $g$. The second analysis was based on a bifactor model of cognitive abilities. For this analysis, we simply extracted the first unrotated factor and interpreted it as $g$. Regarding the distinction between hierarchical and bifactor models, see Jensen and Weng (1994). Because results for the hierarchical model and bifactor model were virtually identical (factor scores for the two models correlated greater than .99), only the results for the hierarchical model are reported. Finally, an extension analysis was performed in which the correlations of $g$ with the 100-Hue and Pitch Discrimination were computed.

To investigate the possibility that our results were due to the inclusion of color-deficient along with color-normal examinees, we used scores on the Color Perception test to exclude the 75 examinees with mild or greater deficiencies in color vision and then repeated our analyses. Because the results were virtually identical, only the results including all examinees are reported.

All analyses were performed using the SPSS for Windows (Release 7.5; 1996) software package. We used listwise deletion of missing values in all factor analyses and pairwise deletion when calculating correlations.

\section{Results}

For the initial error scores on the 100-Hue (prior to the square-root transformations), the mean score was 60.47 , with a standard deviation of 50.79 . This distribution is comparable to

\footnotetext{
Notes to Table 1

Reliability coefficients (from Schroeder, 1988) represent either alpha or split-half reliabilities. $N$ 's for correlations range from 874 to 899 . All correlations greater than .09 are significant at $P<.01$.
} 
the general population distribution reported in the test manual (Farnsworth, 1957). After transformations, the mean score was 44.88 , with a standard deviation of 28.56. Correlations between the 100-Hue and the standard battery tests, excluding Pitch Discrimination (Table 1), ranged from .08 to $.32(M=0.20$, S.D. $=0.07)$. The 100 -Hue's highest correlations were with Paper Folding and Color Perception. The correlation with Color Perception shows that the two tests measure related yet distinct traits.

The mean score on Pitch Discrimination was 62.22, with a standard deviation of 9.62. This distribution is comparable to the general-population distribution reported by Seashore et al. (1940). Correlations between Pitch Discrimination and the other standard battery tests (Table 1) ranged from .03 to $.49(M=0.16$, S.D. $=0.11)$. Pitch Discrimination's highest correlations were with the two other auditory tests, Tonal Memory and Rhythm Memory. These correlations show that these tests also measure related yet distinct traits.

The correlation matrix of cognitive-ability tests is reported in Table 2 . It shows the customary positive manifold of all-positive correlations.

The analyses using a hierarchical model of cognitive abilities yielded four first-order factors, with initial eigenvalues (before rotation) of 4.52, 1.28, 1.11, and 1.04, and one second-order factor $(g)$ (Table 3 ). In the oblique rotation, we allowed the first-order factors to have modest intercorrelations, ranging from .10 to .33. The first first-order factor showed its highest loadings on spatial tests such as Paper Folding, Memory for Design, and Wiggly Block and was interpreted as an index of structural visualization. The second first-order factor showed its highest loadings on memory tests such as Number Memory and Silograms (verbal-associative memory) and was interpreted as an index of memory. The third first-order factor showed its highest loadings on tests such as Number Series, Number Facility, English Vocabulary, and Analytical Reasoning, which are related in content to skills learned in school, and was interpreted as an index of academic ability. The fourth first-order factor showed its highest loadings on tests such as Inductive Reasoning and Observation, which involve

Table 2

Correlation matrix of cognitive-ability tests

\begin{tabular}{llllllllllllll}
\hline & $\mathrm{A}$ & $\mathrm{B}$ & $\mathrm{C}$ & $\mathrm{D}$ & $\mathrm{E}$ & $\mathrm{F}$ & $\mathrm{G}$ & $\mathrm{H}$ & $\mathrm{I}$ & $\mathrm{J}$ & $\mathrm{K}$ & $\mathrm{L}$ & $\mathrm{M}$ \\
\hline (A) Paper Folding & - & .54 & .45 & .26 & .57 & .28 & .28 & .19 & .37 & .21 & .10 & .31 & .10 \\
(B) Wiggly Block & & - & .36 & .24 & .49 & .32 & .24 & .17 & .40 & .31 & .14 & .24 & .14 \\
(C) Number Series & & & - & .46 & .45 & .22 & .36 & .28 & .41 & .25 & .23 & .41 & .29 \\
(D) Number Facility & & & & - & .29 & .25 & .33 & .29 & .43 & .34 & .20 & .26 & .39 \\
(E) Memory for Design & & & & & - & .47 & .43 & .38 & .38 & .32 & .12 & .28 & .19 \\
(F) Observation & & & & & & - & .35 & .27 & .36 & .36 & .13 & .11 & .18 \\
(G) Number Memory & & & & & & - & .47 & .27 & .19 & .09 & .25 & .28 \\
(H) Silograms & & & & & & & - & .30 & .23 & .09 & .39 & .21 \\
(I) Analytical Reasoning & & & & & & & & - & .46 & .18 & .41 & .23 \\
(J) Inductive Reasoning & & & & & & & & & - & .21 & .24 & .26 \\
(K) Ideaphoria & & & & & & & & & & - & .26 & .20 \\
(L) English Vocabulary & & & & & & & & & & & - & .16 \\
(M) Number Checking & & & & & & & & & & & & - \\
\hline
\end{tabular}

Test scores were partialled for sex and age. $N$ 's range from 864 to 899 . All correlations are significant at $P<.01$. 
Table 3

Factor matrix of cognitive-ability tests and correlations of sensory discrimination tests with factor scores

\begin{tabular}{|c|c|c|c|c|c|}
\hline Test & $g$ & $\begin{array}{l}\text { Structural } \\
\text { Visualization }\end{array}$ & Memory & $\begin{array}{l}\text { Academic } \\
\text { Ability }\end{array}$ & $\begin{array}{l}\text { Rapid } \\
\text { Visual } \\
\text { Processing }\end{array}$ \\
\hline \multicolumn{6}{|l|}{ Cognitive abilities } \\
\hline Memory for Design & .77 & .71 & .54 & .19 & .37 \\
\hline Number Memory & .66 & .32 & .73 & .23 & .20 \\
\hline Number Series & .66 & .52 & .39 & .58 & .10 \\
\hline Analytical Reasoning & .65 & .44 & .29 & .52 & .43 \\
\hline Paper Folding & .63 & .80 & .26 & .25 & .15 \\
\hline Observation & .60 & .37 & .43 & .10 & .59 \\
\hline Silograms & .60 & .26 & .62 & .32 & .18 \\
\hline Wiggly Block & .59 & .65 & .21 & .23 & .35 \\
\hline Number Facility & .58 & .27 & .37 & .56 & .28 \\
\hline English Vocabulary & .52 & .37 & .31 & .54 & .06 \\
\hline Inductive Reasoning & .51 & .26 & .18 & .37 & .60 \\
\hline Number Checking & .40 & .09 & .30 & .41 & .24 \\
\hline Ideaphoria & .26 & .14 & .08 & .35 & .13 \\
\hline \multicolumn{6}{|l|}{ Sensory discrimination } \\
\hline 100-Hue & .31 & .34 & .17 & .23 & .15 \\
\hline Pitch Discrimination & .21 & .26 & .11 & .20 & .04 \\
\hline Variance explained & $39 \%$ & $20 \%$ & $16 \%$ & $15 \%$ & $11 \%$ \\
\hline
\end{tabular}

Test scores were partialled for sex and age. Values in the column for $g$ and in the rows for the 100-Hue and Pitch Discrimination represent correlations rather than factor loadings. Variance explained by each first-order factor in the rotated solution was calculated by dividing the sum of squared loadings by the number of cognitiveability tests. Variance explained by $g$ was calculated by dividing the sum of squared loadings on the $g$ factor in the second-order analysis by the number of first-order factors. $N$ 's range from 841 to 843 . All values greater than .06 are significant at $P<.01$.

quickly noticing visual features, and was interpreted as an index of rapid visual processing. The fifth first-order factor, with an initial eigenvalue of only 0.88 , was not retained in the rotated solution.

The first second-order factor showed high loadings on each of the lower-order factors $(0.69,0.70,0.57$, and 0.53 , respectively) and was interpreted as $g$. It showed substantial correlations with nearly all of the cognitive-ability tests $(M=0.57$, S.D. $=0.13)$. The second second-order factor, with an initial eigenvalue of only 0.72 , was disregarded.

The 100-Hue was only moderately related to general intelligence. When the effects of age and gender were controlled, the correlation between the 100-Hue and $g$ was .31. Pitch Discrimination showed a somewhat lower partial correlation of .21 with $g$.

\section{Discussion}

Influenced by Locke's theory that the senses are the building blocks of knowledge, Galton put forth the notion that fine differences in sensory discrimination should be related to individual differences in cognitive ability. Although not inconsistent with Galton's hypoth- 
esis, neither do our results indicate a powerful relation between sensory discrimination and cognitive ability. The correlations between general intelligence and both color discrimination and pitch discrimination are only modest.

The low-to-moderate age-partialled correlation of .21 between a test of pitch discrimination and $g$ in this sample fits into the pattern of modest associations found in previous studies, which reported correlations of .34 with Raven IQ and .29 with Mill Hill IQ in 13year-old schoolchildren (Deary, 1994a), an average correlation of .15 with four ability tests including the Raven and Mill Hill in 11-year-old schoolchildren (Deary, Head, \& Egan, 1989), and a correlation of .08 with Alice Heim 6 Total Scores in second-year undergraduates (Deary, Head, \& Egan, 1989). Our use of a diverse test battery with a sample that was over 15 times the size of the latter undergraduate sample, however, may yield more precise point estimates than in previous studies. The above findings on pitch discrimination, combined with our finding of an age-partialled correlation of .31 between $g$ and a test of color discrimination and with other investigators' findings of age-partialled correlations of .23 and .31 between $g$ and two tests of tactile discrimination ( $\mathrm{Li}$ et al., 1998), form a consistent network of modest associations between sensory discrimination and general intelligence.

The present study can be considered a test of a strong form of the sensory discrimination explanation of $g$, which would predict high correlations between measures of sensory discrimination and $g$. The alternative neural processing speed explanation of $g$, on the other hand, is compatible with low correlations between measures of sensory discrimination and $g$. The modest correlations found in this study between measures of sensory discrimination and $g$ are consistent with the neural processing speed explanation but cast doubt on a strong form of the sensory discrimination explanation.

\section{Acknowledgments}

An earlier version of this article was presented at the July 1999 meeting of the International Society for the Study of Individual Differences in Vancouver, Canada. We acknowledge the support of National Institute on Drug Abuse grants P50-DA09253 and T32-DA07250 and of the Johnson O'Connor Research Foundation, where this study was conducted. We recognize specific contributions by Janine K. Bethscheider, whose study (Bethscheider, 1990) was a forerunner of ours, and Kwang Min Jang, who assisted with data analyses for this study. We are also grateful to Ian J. Deary and Arthur R. Jensen for helpful comments on an earlier version of the article.

\section{References}

Bethscheider, J. K. (1990). The color discrimination project (Technical Report 1990-2). Chicago: Johnson O’Connor Research Foundation.

Cattell, J. M. (1886a). The inertia of the eye and brain. Brain, 8, 295-381.

Cattell, J. M. (1886b). The time taken up by cerebral operations. Mind, 11, 220-242, 377-392, 524-538.

Daniel, M. H. (1980). Reliability of Pitch Discrimination, Wks. 315 FA (Statistical Bulletin 1980-15). Boston: Johnson O’Connor Research Foundation. 
Daniel, M. H. (1982). A factorial study of reasoning tests (Technical Report 1982-6). Boston: Johnson O'Connor Research Foundation. (ERIC Document Reproduction Service No. ED 230 571)

Daniel, M. H. (1983). Aptitudes of physicians (Technical Report 1983-6). Boston: Johnson O'Connor Research Foundation. (ERIC Document Reproduction Service No. ED 288 911)

Deary, I. J. (1986). Inspection time: discovery or rediscovery? Personality and Individual Differences, 7 , $625-631$.

Deary, I. J. (1994a). Intelligence and auditory discrimination: separating processing speed and fidelity of stimulus representation. Intelligence, 18, 189-213.

Deary, I. J. (1994b). Sensory discrimination and intelligence: postmortem or resurrection? American Journal of Psychology, 107, 95-115.

Deary, I. J., Caryl, P. G., Egan, V., \& Wight, D. (1989). Visual and auditory inspection time: their interrelationship and correlations with IQ in high ability subjects. Personality and Individual Differences, 10, 525-533.

Deary, I. J., Head, B., \& Egan, V. (1989). Auditory inspection time, intelligence and pitch discrimination. Intelligence, 13, 135-147.

Farnsworth, D. (1957). The Farnsworth-Munsell 100-Hue Test for the examination of color discrimination: manual (rev. ed.). Baltimore: Macbeth.

Galton, F. (1883). Inquiries into human faculty. London: Dent.

Irwin, R. J. (1984). Inspection time and its relation to intelligence. Intelligence, 8, 47-65.

Jensen, A. R. (1998). The $g$ factor: the science of mental ability. Westport, CT: Praeger.

Jensen, A. R., \& Weng, L.-J. (1994). What is a good g? Intelligence, 18, 231-258.

Li, S.-C., Jordanova, M., \& Lindenberger, U. (1998). From good senses to good sense: a link between tactile information processing and intelligence. Intelligence, 26, 99-122.

Raz, N., Willerman, L., \& Yama, M. (1987). On sense and senses: intelligence and auditory information processing. Personality and Individual Differences, 8, 201-210.

Schroeder, D. H. (1988). JOCRF test reliabilities and interpretation of test scores (Statistical Bulletin 1988-2). Chicago: Johnson O'Connor Research Foundation.

Seashore, C. E., Lewis, D., \& Saetveit, J. G. (1940). Manual of instructions and interpretations for the seashore measures of musical talents. Chicago: Stoelting.

Sharp, S. E. (1898). Individual psychology: a study in psychological method. American Journal of Psychology, 10, 329-391.

Spearman, C. (1904). "General intelligence," objectively determined and measured. American Journal of Psychology, 15, 201-293.

SPSS for Windows (Release 7.5) [Computer software]. (1996). Chicago: SPSS.

Tal, J. S. (1986). Aptitudes of guidance counselors (Technical Report 1986-2). Chicago: Johnson O'Connor Research Foundation. (ERIC Document Reproduction Service No. ED 289 903)

Wissler, C. (1901). The correlation of mental and physical tests. Psychological Review, Monograph No. 3.

Zimowski, M. F., \& Wothke, W. (1988). The measurement of structural visualization: an evaluation of spatial and nonspatial sources of variation in the Wiggly Block and Paper Folding test scores (Technical Report 1988-5). Chicago: Johnson O'Connor Research Foundation. (ERIC Document Reproduction Service No. ED 305 384) 